\title{
0 fandangueiro narrador: a geografia e a modernização do território na música regional caiçara ${ }^{1}$
}

\author{
Bruno Esslinger de Britto Costa ${ }^{2}$
}

${ }^{2}$ Geógrafo, atualmente cursa o programa de pós-graduação (mestrado) em Culturas e Identidades Brasileiras do Instituto de Estudos Brasileiros (IEB-USP), sob orientação do prof. Dr. Walter Garcia da Silveira Júnior.

Recebido em 04/2012. Aceito para publicação em 12/2012.

Versão online publicada em 01/02/2013 (http://seer.ufrgs.br/paraonde)

\begin{abstract}
Resumo: 0 fandango é uma manifestação cultural, que une dança, música e poesia, inerente ao território e à produção dos meios de vida das comunidades caiçaras. Uma expressão que não encontra mais plenas condições de realização no mundo atual, presente sobretudo na região do Lagamar (faixa litorânea entre Iguape-SP e Paranaguá-PR), considerada uma das mais ricas em biodiversidade do ecossistema da mata atlântica. 0 declínio e a individualização da experiência humana como fenômenos da efetivação da modernidade apresentam-se aqui sob uma crítica geográfica. Se produzir o espaço é produzir a própria consciência, reproduzir o espaço é reproduzir uma consciência alheia: estranhamento que se revela na geografia. 0 objetivo do trabalho é percorrer as narrativas e as modas do fandango e do modo de vida caiçara em busca de possíveis caminhos para pensarmos as expressões culturais nas suas relações com a produção do espaço. As reflexões que se seguem reconhecem na música, e na arte, as cisões e contradições intrínsecas à vida moderna sob um modo de produção que se pretende inquestionável na escala global.
\end{abstract}

Palavras-chave: Fandango Caiçara. Tradição e Modernidade. Lagamar

\section{Introdução}

A "arte de narrar está em vias de extinção" escreveu Walter Benjamin em 1936 (BENJAMIN, 1994, p.198), reconhecendo já naquele momento o declínio da faculdade humana de intercambiar experiências. Desde então o abismo entre as gerações tem se aprofundado. E cada vez menos temos algo em comum com as gerações anteriores. 0 fandango é a memória viva de um Brasil que está em extinção; o fandangueiro, seu narrador. Benjamin estava certo quanto ao declínio da tradição oral e da experiência num sentido pleno, "cujas condições de sua realização já não existem na sociedade capitalista moderna"(GAGNEBIN, 1994, p.10).

Tais condições advêm, para Benjamin, justamente do fato de que a experiência transmitida deve ser comum ao narrador e ao ouvinte, um compartilhamento de mundo que se dilui nas rápidas transformações do desenvolvimento técnico-científico do capitalismo, alterando não apenas a paisagem, mas o espaço e o tempo em sua totalidade. Além disso, haveria uma ligação secular entre o gesto e a palavra, possível apenas sob uma organização artesanal do trabalho, cujos ritmos orgânicos se opõem à velocidade e ao estranhamento do trabalho industrial racionalizado, fragmentado. Por fim, a experiência comum e sua transmissibilidade sugerem uma continuação da história narrada, na forma da moral, do conselho. Importante perceber que são as mesmas condições que se relacionam à ideia de "perda da aura", que Walter Benjamin traz em ensaio sobre $A$ obra de arte na era de sua reprodutibilidade técnica (BENJAMIN, 1994).

À mesma época, a partir de 1927, Mário de Andrade empreendeu uma série de viagens ao

${ }^{1}$ Adaptado de pesquisa reunida sob o título O Fandangueiro Narrador: a experiência geográfica e o modo de vida caiçara no processo de modernização do território, apresentada como trabalho final de graduação em geografia na Universidade de São Paulo, sob orientação do prof. Dr. Manoel Fernandes de Sousa Neto. 
Norte e ao Nordeste do Brasil, as quais denominou "viagens etnográficas", reunidas sob o título $O$ turista aprendiz, obra póstuma. As experiências vividas por Mário de Andrade no trajeto tiveram implicações diretas sobre o escritor e o homem público que era. É neste momento que Macunaíma estava em fase de redação e muitas de suas passagens foram inspiradas no aprendizado que teve ao longo das viagens. $O$ turista aprendiz representa o modernista paulistano na busca pelo Brasil real, não-oficial, e suas pesquisas insurgiam contra o que Telê Lopez chama de "posição elitista de seu tempo que congelava o Folclore, dissociando-o dos demais fenômenos da sociedade e reduzindo-o à valorização do 'pitoresco'." (LOPEZ, 1976, p.16).

Apesar de não publicado em vida, a proposta de gênero contida nos seus diários, a narrativa de viagens, combina uma descrição factual com sua subjetividade artística. Lopez aponta que, em suas viagens, Mário de Andrade reconheceu a nossa falta de conhecimento sobre o próprio território:

\begin{abstract}
Viajando pelo Nordeste, nosso cronista nos comunica que ainda há um Brasil por descobrir e valorizar, para ser entendido enquanto vida e cultura do povo. Essa dimensão, a da pesquisa etnográfica e a do enfoque sociológico revelará as danças dramáticas, o catimbó e procurará analisar as condições de vida da região, numa perspectiva nova que deseja abandonar a caracterização do regional através do exótico e do pitoresco, porque estará preocupada com as relações de produção e com as classes sociais. (LOPEZ, 1976, p.41, grifo do autor).
\end{abstract}

O turista aprendiz é uma forma híbrida, fragmentária. Aponta para uma dialética entre a objetividade da documentação e a subjetividade do poeta; entre o Brasil urbano, europeizado, e o Brasil rural, regional; entre a "cultura letrada" e a tradição oral. 0 próprio escritor se confunde com a imagem do moderno e é curioso notar que ele refere a si como "turista aprendiz". Já no prefácio do primeiro diário, escrito anos depois da viagem, em 1943, ele adverte para o estranhamento que sente no trajeto e se diz um "antiviajante":

0 conjunto cheira a modernismo e envelheceu bem. Mas pro antiviajante que sou, viajando sempre machucado, alarmado, incompleto, sempre se inventando malquisto do ambiente estranho que percorre, a releitura destas notas abre sensações tão próximas e intensas que não consigo destruir o que preservo aqui. Paciência[...] (ANDRADE, 1976, p. 49).

É interessante pensar que, assim como Benjamin, Mário de Andrade foi, em sua proposta de gênero híbrido, um escritor de fragmentos. Da sua experiência, podemos ter uma ideia dos paradoxos e conflitos interiores que o "modernista anti-moderno" vivia. E foi um narrador. Em 1928, segundo Flávia Toni, o escritor já dividia com os leitores do Diário Nacional, seus anseios sobre a continuidade da memória musical no Brasil:

"Nossa música popular é um tesouro
prodigioso, condenado à morte. A
fonografia se impõe como remédio de
salvação. A registração manuscrita é
insuficiente porque dada a rapidez do
canto é muito difícil escrevê-lo e as
palavras que o acompanham" (Coluna
"Arte", 24 fev.1928).

A seqüência de seu trabalho etnográfico veio com a realização da Missão de Pesquisas Folclóricas, enviada pelo Departamento de cultura e liderada por Andrade no ano de 1938. Um gravador foi utilizado para registrar as manifestações musicais regionais do Norte e do Nordeste.

"O Brasil realmente não conhece a sua
música nem seus bailados populares,
porque, devido à sua enorme extensão,
e regiões perfeitamente distintas uma
da outra, ni n gu ém, ne nhuma
instituição se deu ao trabalho de coligir
esta riqueza até agora inativa."
("Exposição dos atos e conseqüências
da Missão Folclórica", S. Paulo, 23 de
maio de 1938).

A crítica de Mário de Andrade poderia ter sido escrita hoje. Apesar do maior número de pesquisas etnográficas, antropológicas, folclóricas, e outras, e das maiores possibilidades técnicas de documentação e registro das manifestações regionais, dois processos concomitantes contribuem para que a tendência continue sendo a

${ }^{3}$ TONI, Flávia Camargo. Missão: as pesquisas folclóricas. In: Missão de Pesquisas Folclóricas. SESC - SP. Prefeitura da Cidade de São Paulo. Secretaria Municipal de Cultura. Centro Cultural São Paulo., p. 72.

${ }^{4}$ TONI. Ibid., p. 78. 
extinção das formas elementares e da diversidade da música popular brasileira. O primeiro, como vimos, está no fato de que as condições de realização da experiência a qual chamamos tradicional, como o modo de vida caiçara, desaparecem num ritmo cada vez mais veloz.

0 segundo processo, na realidade, decorre do anterior. Uma vez que, por sua própria condição, o modo de produção capitalista se apropria dos territórios de diferentes formas, a indústria cultural surge como um meio muito eficaz de racionalização do espaço, de homogeneização e subsunção a uma lógica única, a do mercado. 0 universo particular de cada comunidade se dilui juntamente com a variedade de expressões regionais, dando lugar aos novos gêneros populares e mercadorias culturais pensados de "cima para baixo". A efetivação do urbanoindustrial como meio de vida é, no fundo, a única experiência comum a todos nós na modernidade.

\section{"Viagens etnográficas": a geografia e a modernização cantadas nas modas de viola}

Vamos, então, às "viagens etnográficas" do fandango caiçara. Entre as fontes de material de áudio utilizadas no trabalho estão pesquisas no acervo do Museu de Imagem e Som (MIS-SP) e gravações como o cd do "Museu Vivo do Fandango" e o cd duplo intitulado "Viola Quebrada e Família Pereira". Nele, encontram-se algumas das modas ${ }^{5}$ tradicionais da região do Lagamar. Da pesquisa em campo também foi possível transcrever algumas modas.

Os versos de uma chamarrita cantada pela Família Pereira já nos remete ao começo do trabalho, onde reconhecemos a origem portuguesa do fandango e sua chegada ao Brasil, no Rio de Janeiro, como um gênero urbano das classes altas que foi gradativamente sendo levado ao meio rural.

\section{(...)Fui eu que mandei buscar, ai A chamarrita do Rio, ai, moreninha $O$ dondom de Portugal, ai Ai, ai do Rio, ai, o dondom de Portugal $l^{6}$}

Acerca da origem, Segismundo Spina ressalta algumas especificidades da poesia lusitana, por exemplo, na métrica:
Pois não se fala na especificidade rítmica de certas línguas? Que a língua portuguesa, por exemplo, apresenta um ritmo descendente na expressão da frase, em oposição ao francês, onde o ritmo ascendente é característico? Que o verso redondilho é tipico das línguas ibéricas na conversação, como é na inglesa e no grego antigo da conversação o metro jâmbico? (SPINA, 2002, p.22)

A morfologia é, portanto, fundamental na busca pelas origens das manifestações musicais, uma vez que poesia e música não se dissociavam nas suas formas elementares. As modas e toadas do fandango são, em sua maioria, compostas por versos redondilhos de sete sílabas (redondilho maior), reiterando suas influências predominantemente ibéricas.

$$
\begin{aligned}
& E S-T E-P E I-T O-Q U E A-Q U I-C A N(T a) \\
& E-P E I-T O-D E-D O I S-I R-M \tilde{A} O S \\
& C A N-T E-M O-P E I-T O-C O M-P E I(T o) \\
& C O-R A-C C \tilde{A} O-C O M-C O-R A-C C \tilde{A} O^{7}
\end{aligned}
$$

Falar apenas em suas origens geográficas seria insuficiente. Como se desenvolveu o fandango nas comunidades caiçaras? Se produzir o modo de vida é produzir a consciência (MARX e ENGELS, 1986), é preciso voltar às formas de viver que essas comunidades desenvolveram, expressas no mutirão e na música. Em $\mathrm{Na}$ madrugada das formas poéticas, Spina também desenvolve a importante e pouco compreendida relação entre o ritmo e o trabalho (SPINA, 2002). A ideia concebida por Aristóteles de que o ritmo seria "inerente" ao homem é fundamental para entender a música em relação aos modos de vida, principalmente pelo fato de que, na sua origem, haveria uma unidade entre a música, a dança e a poesia.

Falar apenas em suas origens geográficas seria insuficiente. Como se desenvolveu o fandango nas comunidades caiçaras? Se produzir o modo de vida é produzir a consciência (MARX e ENGELS, 1986), é preciso voltar às formas de viver que essas comunidades desenvolveram, expressas no mutirão e na música. Em Na madrugada das formas poéticas, Spina também desenvolve a importante e pouco compreendida relação entre o ritmo e o trabalho (SPINA, 2002). A ideia concebida por Aristóteles de que o ritmo seria "inerente" ao

\footnotetext{
${ }^{5}$ As modas (ou modas de viola) são as formas de expressão da música caipira. No caso do fandango caiçara as mais comuns entre as modas bailadas são a chamarrita e o dandão (ou dondom). Também há modas batidas (tamanqueadas) como o Anu, o Sinsará, a Queromana, a Tonta, entre outras.

${ }^{6}$ Chamarrita (Moreninha). Cd “Viola Quebrada e Família Pereira” (faixa 1 - disco 2)
} 
homem é fundamental para entender a música em relação aos modos de vida, principalmente pelo fato de que, na sua origem, haveria uma unidade entre a música, a dança e a poesia.

A poesia primitiva, entretanto, não é exclusivamente a poesia dos povos préletrados, mas a poesia que está ligada ao canto, indiferenciada, anônima e coletiva. É a poesia no seu estágio ancilar, isto é, subordinada à música e às vezes à coreografia, mais especialmente àquela. Daí o campo de nossas indagações abranger não só as manifestações poéticas dos povos naturais, como também aquelas que se situam na infância ou na madrugada dos povos atuais. A função ancilar da poesia está representada pela associação em que viveu com a música, de certo modo com a dança, antes que surgisse a pessoa do poeta, a poesia individual. E aqui poder-se-ia objetar: a pessoa do poeta só apareceu quando a poesia se dissociou da música? No estágio ancilar a poesia é inevitavelmente anônima? A chamada poesia democrática, a poesia como criação coletiva, não existe. A poesia primitiva é uma poesia de caráter coletivo porque representa os anseios da coletividade e está intimamente ligada ao modus vivendi dessas comunidades; a sua realização poética, entretanto, atribui-se a uma tête poétique, alguém que na tribo se distinguiu por essas qualidades. (SPINA, 2002, p.15)

É preciso, pois, pensar o fandango sob esta unidade (música-dança-poesia). E sob a unidade do universo caiçara, representado pela religiosidade e pelo trabalho, respectivamente o seu universo espiritual e o seu universo sensível. 0 fandango seria o lado profano de uma religiosidade expressa na devoção a São Gonçalo, na bandeira do Divino Espírito Santo, na Folia de Reis. Alceu Maynard de Araújo ressalta o fato de que acabado o trabalho no mutirão, antes do início do "bate-pé", a primeira dança era oferecida a São Gonçalo: "Após os trabalhos do mutirão, o promotor dêste, para a alegria dos trabalhadores, realiza um Fandango e, antes de começar a função de bate-pé, há uma dança dedicada a São Gonçalo[...]" (ARAÚJO, 1967, p.133).
Em relação ao universo de sua reprodução material, Spina nos chama a atenção para a confusão que fez muitos pesquisadores atribuir a origem da música e do canto "como disciplina e suavização do trabalho corporal". Para além de uma expressão do trabalho de mutirão, a música caiçara também representou um importante fator de circulação dos indivíduos e com isso suas histórias cotidianas, num tempo em que não havia qualquer meio de comunicação à distância na região ${ }^{8}$. E isto é reconhecido pelo autor já nas formas primitivas da poesia, que não se encerram no aspecto mágicoreligioso.

Ao lado de uma poesia tradicional, de interesse coletivo, intimamente ligada aos rituais mágico-religiosos da comunidade, pratica-se uma poesia circunstancial, que versa os temas mais variados, sobretudo profanos, de amor, de guerra, recordações de fatos da vida diária, de sátira aos viajantes estrangeiros. A poesia no seu estágio primitivo não é, portanto, exclusivamente ritual - como pretende o grande musicólogo. É inegável que a magia e a religião foram as duas fontes mais fecundas de onde as artes rítmicas extraíram a sua substância, os seus materiais, através da mimetização. (SPINA, 2002, p. 32)

A mimetização, portanto, estaria em sua origem na própria relação do homem com o mundo exterior sensível.

0 mimetismo é o traço fundamental do pensamento primitivo: mimetismo dos fenômenos vegetais, dos atributos e qualidades dos animais, dos atributos dos Espíritos, enfim, de todas as emoções que o mundo ambiente desperta na alma do homem primitivo. A mimetização realiza-se, pois, através da grande trilogia: a Dança, a Música e a Poesia, que, associadas à linguagem e à mímica expressiva, acordam e exteriorizam os escalões subterrâneos da vida sentimental. (SPINA, 2002, pp. 32-33)

0 fandango canta o caiçara em sua universalidade. Voltemo-nos às modas para analisar o declínio deste modo de vida através da modernização do território e sua efetivação na

${ }^{8}$ As modas (ou modas de viola) são as formas de expressão da música caipira. No caso do fandango caiçara as mais comuns entre as modas bailadas são a chamarrita e o dandão (ou dondom). Também há modas batidas (tamanqueadas) como o Anu, o Sinsará, a Queromana, a Tonta, entre outras. 
sociedade urbano-industrial. Primeiramente, a falsa associação que fazemos hoje entre o caiçara e o "pescador exclusivo", pode ser questionada pelas inúmeras modas com referências ao trato com a terra, à vida no campo:

\section{Fui no mar colher laranja Fruta que no marnão dá Vim de lá todo orvalhado Da onda que vai e vem... ${ }^{10}$}

As modas narram a vida rural, o cotidiano do caiçara. Suas histórias revelam as transformações sofridas pelo caiçara, os diversos tempos e espaços de sua vida. Modernidade e tradição, História e Geografia, cantadas em versos, como no dondom Avião no estrangeiro:

\section{Estava na minha roça, meu bem Eu estava trabalhando, meu bem Escutei uma toada, meu bem Que pro aria voando Éo avião no estrangeiro Oi lai, meu bem Que ia pro Rio de Janeiro ${ }^{11}$}

Entre a terra e o mar, a maioria das modas narram o amor, a saudade e o "ser violeiro". Mas o conteúdo não se resume à temática. É muito significativo o fato de cada moda ter várias toadas, ou seja, seus versos são muitas vezes comuns a outras modas, têm seu uso livre. 0 mesmo não ocorre em relação aos passos da dança, sobretudo no fandango batido, em que se verifica uma maior complexidade nas muitas convenções, que alternam palmas, tamanqueados e diferentes movimentos entre homens e mulheres.

Muitos trabalhos concentraram-se nas coreografias do fandango, ou em sua estrutura harmônica e rítmica, pois cada moda tem um toque de viola que lhe é próprio, um tamanqueado. Poucos, porém, dão a devida atenção ao fato de a harmonia ser, de certa forma, simples: a progressão varia, em quase todas as modas, em torno do acorde de tônica ( $1^{\circ} \stackrel{o}{\text { grau}}$ ) e de dominante
(50 grau). Mas esta aparente simplicidade traduzida nos poucos acordes vai muito além, pois acima de tudo confere um caráter de liberdade ao cantador.

Em primeiro lugar, pela ênfase na história contada, ou seja, na voz do violeiro, em sua mensagem, sua narrativa. Em conversa com fandangueiros, eles deixam muito claro a identidade como músico sertanejo, cantador. 0 caráter da oralidade na transmissão dos conhecimentos musicais representa uma possibilidade maior de integração e participação em uma experiência coletiva. É extremamente importante lembrarmos que não há uma dissociação entre a música e a dança e que o fandango não é em sua origem um espetáculo musical. E justamente neste ponto entra uma reflexão fundamental: ser músico na comunidade caiçara tem um significado muito amplo e a execução do instrumento é apenas uma de suas atividades, que envolvem também a construção dos instrumentos e dos tamancos de madeira e o ensino dos passos da dança: a música não é uma profissão, tampouco um produto.

A liberdade se expressa no fato de não existirem versos específicos para cada moda. Muitas vezes há toadas que se repetem em modas diferentes. Isso confere ao cantador a possibilidade de buscar no repertório tradicional versos conhecidos, ou mesmo improvisar, ao chamar a moda e se despedir dela, como na chamarrita abaixo:
(...) Vamos dar a despedida Meu camarada irmão, ai, moreninha Meu camarada irmão, ai A despedida, meu camarada irmão, ai Meu camarada irmão Eu por vós dou minha vida, moreninha Por outro darei ou não, ai Dou minha vida, por outro darei ou não ${ }^{12}$

Agora, um Sinsará, moda batida:

\section{(...)Vamos dar a despedida}

${ }^{9}$ Sobre a falsa associação do caiçara como "pescador exclusivo", Luiz Geraldo Silva (2004)diz: "Sinteticamente, pode-se dizer que, em passado relativamente recente, o "caiçara” tinha relação apenas secundária com o mar. Este não se constituía num referencial cultural central de seu modo de vida. Sua visão de mundo, suas festas, seus rituais, suas noções de tempo e espaço não acenavam prioritariamente para uma relação entre sua comunidade e o meio marítimo, mas, antes, se assentavam, sobretudo na sua relação com a terra, com os ritmos da produção agrícola. 0 mar ocupava posição apenas secundária na configuração de sua visão de mundo. Ele não era um "pescador exclusivo", como atualmente, mas um pescador eventual que explorava o mar de dentro e os estuários esporadicamente em sua canoa rústica; nos meses do inverno dirigia-se à linha da praia em grupos numerosos para fazer o lanço da tainha e, assim, pescava para complementar suas necessidades alimentares e ganhar algum dinheiro num mercado incipiente."

${ }^{10}$ Dondom (Uma noite ao luar). Cd "Viola Quebrada e Família Pereira” (faixa 6 - disco 2)

${ }^{11}$ Dondom (Avião no estrangeiro). Cd "Viola Quebrada e Família Pereira” (faixa 3 - disco 2)

${ }^{12}$ Chamarrita (Moreninha). Cd "Viola Quebrada e Família Pereira” (faixa 1 - disco 2)

${ }^{13}$ Sinsará. Cd "Viola Quebrada e Família Pereira” (faixa 7 - disco 2) 


\section{Prafazer a moda curta \\ Prafazer a moda curta \\ Quem faz a moda comprida \\ Tá arriscado a pagar murta \\ Tá arriscado a pagar murta \\ Encontrei com o Sinsará... ${ }^{13}$}

A "murta" não é uma quantia em dinheiro. Entre as regras do fandango há uma em que caso o beneficiado do mutirão tire uma dama para dançar, é obrigado a pagar uma rodada de cachaça como multa. As modas não seguem necessariamente um padrão de tempo de execução e ao final dos versos, o caráter cíclico permite ao cantador voltar ao começo quantas vezes quiser:

\section{(...) Despedida, despedida, \\ Eu não posso mais cantar \\ Eu largando da viola \\ Outro que venha tocar... ${ }^{14}$ \\ [volta ao primeiro verso]}

Os fandangueiros ainda recordam o tempo em que só era preciso comprar sal e querosene. Hoje, a necessidade de ganhar dinheiro para adquirir produtos industrializados é a experiência comum a todo o território. Uma geração que cresceu nos sítios, produzindo todo o seu alimento, sem energia elétrica ou conta em banco, convive hoje com a televisão, a internet, o celular. Seria mesmo a última geração do fandangueiro narrador? Com efeito, as tradições inserem-se, atualmente, num mecanismo de mercado, e muitos têm no artesanato e no turismo, sua principal fonte de rendimentos. Em um dondom de autoria desconhecida, gravado para o projeto Museu Vivo do Fandango, fica evidente, para além da relação com a lavoura e com a terra, o estranhamento frente à lógica externa do dinheiro:

Quando eu pego na viola
Eu já sei por quem pergunto
Como fica tão bonito
Dois amigos cantar junto
Essa compra de palmito
Tá pior que cativeiro
Quem tira não ganha nada
Quem compra ganha dinheiro
Essa compra de palmito
Não dá nada pra ninguém
Quem tira não ganha nada
Quem compra dinheiro tem
Essa compra de palmito
É melhor se acabar

Que o povo se desengana Na lavoura vai cuidar... ${ }^{15}$

A extração ilegal do palmito é o sustento de muitas famílias, apesar da escassez do juçara e do pouco dinheiro que os palmiteiros ganham com a atividade. 0 dandão acima deixa claro que o caiçara tem plena consciência de sua posição na hierarquia de classes: "Quem tira não ganha nada, quem compra dinheiro tem." $\mathrm{Na}$ condição de expropriados do seu modo de vida tradicional e do seu próprio território, o corte do palmito torna-se uma alternativa de sobrevivência muitas vezes única, apesar do risco envolvido.

Atualmente há iniciativas de manejo sustentável do juçara, pela extração de sua polpa, para o consumo como o açai da amazônia. Em novembro de 2010, inclusive, foi realizado em Registro o primeiro encontro da Rede Juçara, que reúne organizadores e produtores que trabalham com a espécie. Apesar de incipiente, a atividade tem se apresentado como uma possível alternativa ao corte ilegal.

Segundo Luiz Geraldo Silva, foi a partir da marginalização econômica e social deste modo de vida que surgiu a associação do caiçara à figura do "pescador exclusivo" (SILVA, 2004). Na moda que se segue é possível entender como a atividade pesqueira é decorrência de uma inserção negativa do caiçara na economia de mercado:

Sou um pobre pescador, ai
Que vivo em alto-mar
Me levanto bem cedinho, ai
Para o meu pão ganhar
Acordo de madrugada
Minha Mãe está de pé
Preparando a marmita
Temperando meu café
Quando eu estou saindo
Minha mãe me abençoa
Pede que Deus me acompanhe, ai
Pra que a pesca seja boa $(. . .)^{16}$

Logo nos primeiros versos a cisão entre o trabalho e a produção dos próprios meios de vida já se estabelece. Ora, se a pesca em sua origem é uma atividade tradicional da comunidade caiçara, seu caráter inerente se desfaz na necessidade de ganhar o pão, como um meio para obter a finalidade do dinheiro. E o caiçara reconhece, em sua experiência cotidiana, as contradições desta racionalização do seu trabalho:

\footnotetext{
${ }^{14}$ Dandão: meu amor mandou uma carta (tradicional). "Museu Vivo do Fandango" (CD1 - São Paulo, faixa 26)

${ }^{15}$ Dandão: Compra de palmito (tradicional). Fonte: "Museu Vivo do Fandango" (CD1 - São Paulo, faixa 20)

${ }^{16}$ Dandão: Pobre Pescador (Valdemir Antônio Cordeiro "Vadico"). Fonte: "Museu Vivo do Fandango" (CD1 - São Paulo, faixa 22)
} 

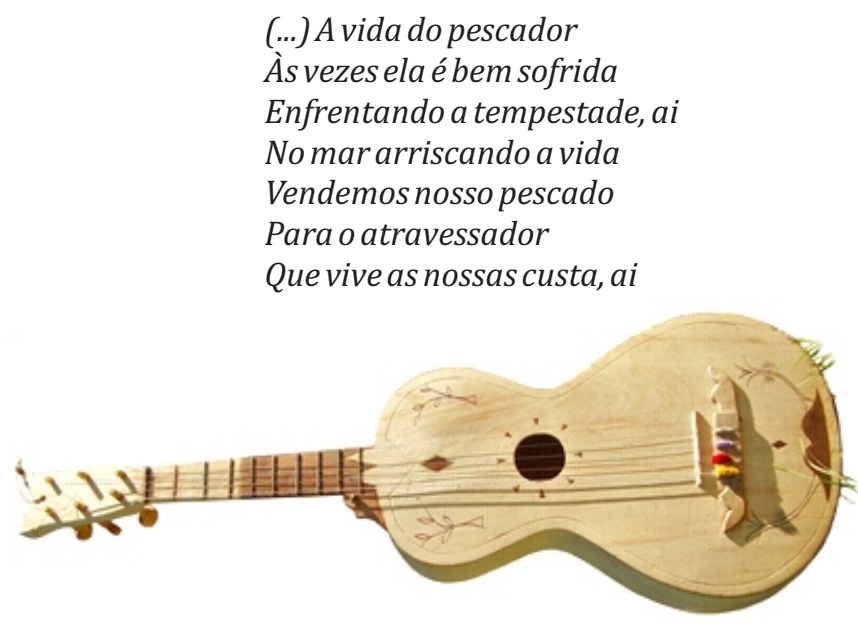

Sea onaa nao me levar

Vamos dar por despedida

Que eu tenho por descansar

Amanhã eu vou cedinho, ai

Pra pescar em alto-mar... ${ }^{17}$ cerco e o próprio fandango, sobrevivem residualmente, à deriva entre a memória de um passado que já não existe e um futuro de eternas promessas.

Pescador que sofre éo artesanal

Quando o guarda vem me escondo no mangal

É os "home" da lei e a fiscalização

O meu gerivaléo meu ganha-pão

Vou pescar bem cedo sem tomar café

E a minha mulher fica reclamando

Quando eu tô dormindo me ponho a sonhar

No meu gerival tem camarão entrando

O remo é o motor de um cavalo só

Quando chuva échuva, quando solésol Veja quanto sofre um pescador

Que trabalha tanto e não tem valor

Pesco de enchente, maré de vazante

Pesco com a chuva, com a trovoada Praganhar sustento pra minha família

Pesco todo dia também de madrugada

Vamos dar por despedida

Hoje sim, amanhã não

Hoje navega meus peitos

E amanhã meu coração ${ }^{18}$

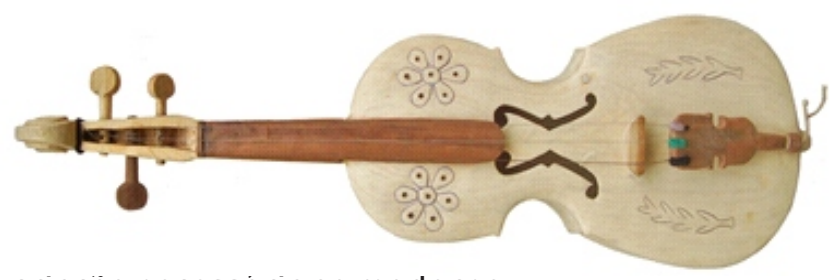

criaçào necessảria ao moderno.

Ofandango Deus deixou

Pro regalo da pobreza

Que me faz chorar

Quem se mete no fandango

Não se lembra da riqueza

Que me faz chorar ${ }^{20}$

Fig. 2: Rabeca Caiçara construída por Arnaldo Pereira - Ariri SP (acervo pessoal)

As modas não são cristalizadas. E é possível

${ }^{17}$ Id.

${ }^{18}$ Chamarrita: Pescador Artesanal (Paulo Jesus Pereira). Fonte: “Museu Vivo do Fandango" (CD1 - São Paulo, faixa 2)

${ }^{19}$ Para lembrar a expressão utilizada por Vidal de La Blache (1954).

${ }^{20}$ Dondom (Fandanguinho). Cd "Viola Quebrada e Família Pereira” (faixa 11 - disco 1) 
perceber importantes diferenças entre modas tradicionais e as de composição mais recente. Os conhecimentos musicais são transmitidos pela tradição oral e se a memória do caiçara pôde preservar seus versos, o mesmo não se pode dizer da autoria das modas, na maioria das vezes desconhecida. Apesar disso, no material de áudio pesquisado, sobretudo o Museu Vivo do Fandango (muito rico pela diversidade de grupos registrados), encontram-se não somente modas tradicionais mas também algumas de compositores identificados. Aqui se exige muita atenção, do contrário podemos superestimar o superficial, ou seja, considerar apenas a época das modas ou a impossibilidade técnica de gravá-las como responsáveis pelo seu anonimato. A propriedade intelectual é inerente à existência da cultura como uma mercadoria, como uma indústria, e por isso, contraditória a uma prática como o fandango.

Neste ponto precisamos voltar à gênese do modo de vida caipira caiçara. Se a ausência de propriedade intelectual das modas se define temporalmente em oposição ao presente, enquanto espaço ela se define por aquilo que Antonio Candido chamou de "provisório da aventura", impresso na estrutura instável, na habitação, na dieta, nas técnicas e usos rudimentares, nas tradições e até no caráter do caipira, assentado sobre o "mínimo vital":

\begin{abstract}
A impressão de duração, baseada na solidez das habitações européias falta aqui de todo, mas, em verdade, não deixando de ser adequada ao clima; o morador, cuja residência não tem estabilidade, não precisa de teto duradouro.(CANDIDO, 2001, p.48)
\end{abstract}

Não seria da ausência de uma "impressão de duração" que estaria a origem da relação do caiçara com a propriedade privada?

A esta rudeza correspondiam técnicas e usos igualmente rudimentares. Segundo os informantes anciãos do grupo que estudei - e que para responder sondavam não apenas a memória infantil, mas a tradição ouvida de pais e avós - antigamente a "gente do sítio" fazia tudo e raramente ia ao comércio, comprar sal. Não havia quase negócios; cada um consumia o seu produto e nos anos fartos sobrava mantimento, que não "tinha preço".
(CANDIDO, 2001, p. 49)

Ausência, esta, que surge ao mesmo tempo como causa e efeito da impossibilidade de acumulação numa sociedade em que a propriedade de escravos e, num segundo momento, a propriedade fundiária, constituíram-se bases da riqueza.

\begin{abstract}
"Em geral, o caiçara não acumula bens. Até 1954, quando se iniciou em Ubatuba a corrida de terras, que antes dessa época não apresentavam valor especial, vivia tranqüilo em seu terreno ou posse; ninguém disputava sua terra e ele não se dava conta do valor que esta poderia vir a ter. Pescava e plantava o suficiente para comer" (SETTI, 1985, p.28)
\end{abstract}

O conteúdo dos versos é ilustrativo. Enquanto as modas mais antigas têm na relação com a terra e no amor sua temática principal, muitas das composições recentes carregam uma mudança qualitativa das suas narrativas ao cantar a questão monetária, a paisagem urbana, a racionalização do artesanato...

Eu estava imaginando problema da vida minha

Fui jogar na loteria só pra ver se a sorte vinha

Se ganhava algum dinheiro no jogo da raspadinha

Eu nunca ganhei prêmio no jogo da loteria

Não gosto da raspadinha pois é um jogo que avicia

Seje velho ou seje moço, está raspando todo dia

Conversando com um colega sobre a vida apertado

Eu perguntei pra ele se ele já tinha jogado

Ele então me respondeu que também tinha raspado

Foi aí que eu descobri que a raspadinha não dá nada

Aí encontrei com uma mulher e tive pena da coitada

Pois ela estava raspando sentadinha na calçada

Quero dar por despedida meu camarada irmão

Eu por vós dou minha vida, por outro darei ou não $(. . .)^{21}$

\footnotetext{
${ }^{21}$ Dandão: Jogo da Raspadinha (Armando Teixeira). Fonte: “Museu Vivo do Fandango” (CD1 - São Paulo, faixa 4)
} 
Do mesmo compositor, também há uma moda sobre a cidade de Cananéia, muito significativa por reunir a diversidade de espaçotempo coexistentes, o espaço geográfico que Milton Santos definiu como "acumulação desigual dos tempos" (SANTOS, 2004):

\section{Vou falar d'algumas coisas \\ Do que Cananéia tem \\ Tem balsa da travessia \\ Na praça tem seu canhão \\ Tem vários supermercados \\ Ea matriz de São João \\ Tem a rua Pedro Correa \\ Tem a rua do Artesão $0^{22}$}

Uma característica importante da modernização dos territórios é justamente a criação de espaços racionalizados, como se vê pela presença de uma rua destinada à venda do artesanato local: o espaço valor-de-troca, funcional. Além disso, as narrativas também trazem aspectos da vida econômica, como a atividade turística.

Tem a rua Tristão Lobo
Onde mora o tubarão
Tem sua velha figueira
Ceagesp e Hotel Glória
Avenida Independência
Pra completar sua história
A Praça Martim Afonso
Retratado na memória
Tem Carijo e Acaraú
Eo porto de Cubatão
Etem a linda paisagem
Do Morro de São João
Cananéia abençoada
É uma terra de oração
Cananéia é um paraíso
Que os turistas descobriu
Por ser uma das cidades
Das mais velhas do Brasil
Tem a ponte da Aroeira
Tem a Praça do Rocio
Daqui só resta saudades
Pra quem veio e pra quem viu
Eu vou darpor despedida (...)

De fato, a evolução das modas aponta na direção da modernização do território caiçara, do declínio de sua tradição e, de extrema importância para a geografia, da perda da experiência de uma vida rural e a consolidação de um padrão de vida e de consumo negativos porque sem recursos, e sem a constituição do urbano como um modo de vida em efetivo, exceto pela determinação da forma mercadoria.

\section{O rural e o urbano}

A dialética entre o rural e o urbano é, portanto, reconhecida como estranhamento. A apropriação gradual dos espaços rurais pela dinâmica da cidade se dá através da transformação da atividade nrodutiva e sulas formas tradicionais em

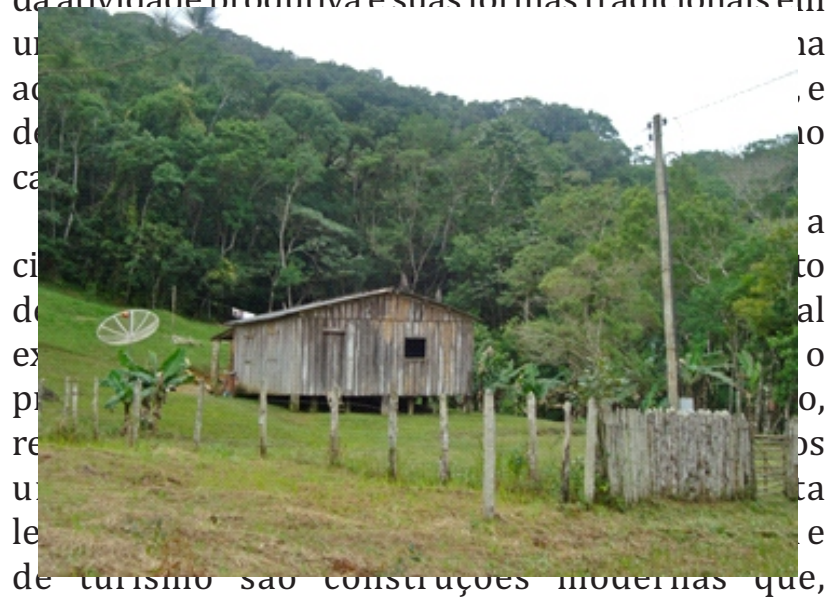
incorporando imensos territórios, submetem as populações locais a condições que lhes são alheias. No fundo, significa um processo de aprofundamento da divisão do trabalho no modo de produção capitalista.

Fig 3: Modernidade e Tradição; Global e Local. Ariri - SP

\footnotetext{
${ }^{23}(. .$.$) And as the moneyed order of the city extends in importance, where does much of the new capital go, but back to the land to$ intensify the exploiting process? (...) The exploitation of man and of nature, which takes place in the country, is realised and concentrated in the city. WILLIAMS, Raymond. The Country and The City. Oxford University Press, New York,: 1973, p. 48.

${ }^{24}$ Sobre a relação entre as comunidades caiçaras e a criação de parques e reservas, ver: DIEGUES, Antonio Carlos Sant'anna. 0 patrimônio cultural caiçara. In: DIEGUES, A. C. (org.) Enciclopédia Caiçara - Volume 5: festas lendas e mitos caiçaras. São Paulo: HUCITEC, NUPAUB, CEC/USP, 2006.,

${ }^{25}$ Extraído de conversas com músicos caiçaras durante o mês de julho de 2010, período em que realizei um trabalho de imersão na região. Outros trabalhos e entrevistas foram resultado da participação na "Semana Cultural do Ariri" (2010 e 2011), na Escola Estadual Péricles Eugênio da Silva Ramos, e ao longo do ano de 2011.
} 
(acervo pessoal)

Como pudemos perceber nas letras das modas, o caiçara do Lagamar sabe muito bem o significado da alienação pois ainda possui a experiência e a riqueza da diversidade (à qual se acrescentou o prefixo "bio" mais recentemente). 0 reconhecimento que tem do mundo veiculado na mídia ou a possibilidade de conhecer outros lugares permitem-no sentir na pele o sentido da apropriação de seu território, inclusive sob a forma de unidades de conservação da natureza. Tanto que vê "a lei ambiental" como causa principal do declínio do fandango e, principalmente, de seu modo de vida ${ }^{24}$.

Qual não é o estranhamento de um fandangueiro de Rio dos Patos (PR), quando diz ter visto apenas soja na paisagem durante trajeto até Londrina, onde fora se apresentar. "Ninguém mais sabe o que é um Ingá ${ }^{25}$ ". Ele tem consciência que esta pobreza da experiência moderna faz parte da mesmas contradições que o impedem de continuar sendo caiçara em todos os seus sentidos, ao questionar o motivo pelo qual tiram seu direito de derrubar a mata para sua subsistência se "lá em cima" já derrubaram e continuam a cortar imensas áreas em favor de apenas um gênero agrícola, da indústria, do agronegócio, da urbanização.

Evidentemente tudo o que foi dito contribui para uma análise geográfica que, no entanto, ficaria incompleta se perdermos de vista o sentido da formação do território brasileiro nos termos de Caio Prado Júnior (1999), ou seja, a inserção do território na divisão internacional do trabalho como um processo de satisfação da demanda externa do capitalismo de centro em suas diversas fases, sobretudo hoje.

Walter Benjamin havia reconhecido, já no início do século XX, que a arte de narrar estava em vias de extinção. Hoje, frente à globalização, teríamos ficado ainda mais pobres em experiências comunicáveis - um paradoxo, dada a multiplicidade dos meios de comunicação na era da informação digital. A ruptura entre passado e futuro descrita por Hannah Arendt é sintomática ${ }^{26}$. São cada vez menos os que ainda resguardam experiências transmitidas pelos pais, pelos avós, de tempos insondáveis. 0 fandangueiro é um narrador e está em vias de extinção enquanto tal. 0 fandango, porém, pode continuar existindo enquanto houver possibilidades para sua positivação na sociedade moderna, seja através editais públicos, de espetáculos musicais, do seu reconhecimento como cultura tradicional.
Uma vez que uma das principais preocupações deste trabalho é não romantizar as experiências ditas tradicionais, há aqui uma questão importante. Pois no limite, existe um sério debate sobre o direito a uma vida digna na sociedade moderna, afinal é nela que estamos todos inseridos. E se, talvez, o fandangueiro de outrora esteja em suas últimas narrativas, o futuro das comunidades caiçaras pode ter no fandango uma fonte de resistência e de afirmação de uma identidade territorial que lhes é própria. Como o rap das periferias, haveria na expressão artística um caminho para se conquistar espaço e ter direito à voz numa sociedade que nos cala todos os dias com o excesso de informações e produtos culturais pré-fabricados.

\section{Referências}

ANDRADE, Mário de. O turista aprendiz; estabelecimento de texto, introdução e notas de Telê Porto Ancona Lopez. São Paulo, Duas Cidades, Secretaria da Cultura, Ciência e Tecnologia, 1976.

ARAÚJO, Alceu Maynard. Folclore Nacional, volume II: Danças, Recreação, Música. São Paulo: Melhoramentos, 1967.

ARENDT, Hannah. Entre o passado e o futuro. $5^{\mathrm{a}}$ ed. São Paulo: Perspectiva, 2005.

BENJAMIN, Walter. Magia e Técnica, arte e política: ensaios sobre literatura história da cultura / Walter Benjamin; tradução Sérgio Paulo Rouanet; prefácio Jeanne Marie Gagnebin. - 7 a Ed. - São Paulo: Brasiliense, 1994 (obras escolhidas v.1).

CANDIDO, Antonio. Os parceiros do Rio Bonito. Estudo sobre o caipira paulista e a transformação dos seus meios de vida. Editora 34, Duas Cidades: 2001.

DIEGUES, Antonio Carlos Sant'anna. O Mundo caiçara: o olhar do pesquisador. In: DIEGUES, A.C. (org.). Enciclopédia Caiçara - volume 1: O olhar do pesquisador-- São Paulo, Hucitec. NUPAUB: CEC / USP, 2004.

. O patrimônio cultural caiçara. In: DIEGUES, A. C. (org.) Enciclopédia Caiçara - Volume 5: festas lendas e mitos caiçaras. São Paulo: HUCITEC, NUPAUB, CEC/USP, 2006.

GAGNEBIN, Jeanne Marie. Walter Benjamin ou a história aberta (Prefácio). In: BENJAMIN, Walter. Magia e Técnica, arte e política.. op.cit.

LA BLACHE, Vidal de. Princípios de Geografia Humana. 
In: A Marcha da Humanidade volume 1: Geografia Histórica - 2 ${ }^{\text {a }}$ edição, revista - Lisboa: Cosmos, 1954.

LOPEZ, Telê. "Viagens etnográficas" de Mário de Andrade. In: ANDRADE, Mário de. O turista aprendiz; op. cit.

MARX, Karl \& ENGELS, Friedrich. A ideologia Alemã, 5a edição - São Paulo: Hucitec, 1986.
PIMENTEL, Alexandre; GRAMANI, Daniella; CORRÊA, Joana (orgs.) Museu Vivo do Fandango. Associação Cultural Caburé, 2006.

PRADO Jr. Caio, O sentido da Colonização, In: Formação do Brasil Contemporâneo, SP, Brasiliense, 1999.

TONI, Flávia Camargo. Missão: as pesquisas folclóricas. In: Missão de Pesquisas Folclóricas. SESC - SP. Prefeitura

\title{
The storyteller fiddler: geography and the modernization of the territory in caiçara regional music
}

\begin{abstract}
Fandango is a cultural manifestation that gathers dance, music and poetry, and is inherent to the territory and means of production of the traditional Caissaras communities. It is an expression that can't find conditions for realization in present times, remaining in remote and preserved areas of São Paulo and Paraná State Coast. The fall in value of experience and its individualization as phenomena of modernity appear here under a geographical critique. If the production of space is the production of consciousness itself, then the reproduction of space is the reproduction of an alien counsciousness: an estrangement that is revealed through geography. The aim of this paper is to explore the narratives and songs of the Fandango and the caissara way of life in search for varying methods of analysis of cultural expressions in their relations to the production of space. These reflections acknowledge within music, and generally within art, the disjunctions and contradictions intrinsecs to the modern life under a mode of production that pretends to be unquestionable in a global scale. Keywords: Folk Music. Tradition and Modernity. Caiçara. Lagamar.
\end{abstract}

